\title{
Mathematical Analysis of PSF (Proportion Spent on Food) in Specific Communities
}

\author{
Rama Mohan Rao Matta ${ }^{1}$, Chandrasekhar Putcha ${ }^{2}$ \\ ${ }^{1}$ GITAM Institute of Management, GITAM (Deemed to be University),Visakhapatnam, India, rbachi123@gmail.com \\ ${ }^{2}$ Department of Civil and Environmental, California State University, Fullerton, USA, cputcha@fullerton.edu
}

\begin{abstract}
This paper is mainly based on establishing a relation between PSF (Proportion Spent on Food) and factors affecting poverty in India. The work is mainly based on the doctoral thesis of the first author (Rao 1995). Seminal work was done and reported in various conferences/Journals in India (Rao 1998). The collaboration between the Indian and American faculty lead to this research paper. The data used in the analysis is that of fisherman community in the eastern part of India. PSF has been shown to be a critical parameter. It was reported (Rao 1998) that based on the grouped per capita monthly expenditure spent on food (PSF), the pattern of change in PSF lies in the range of 79.1 and 83.8. The present research study is based on a detailed mathematical analysis of the poverty data as related to fisherman. It establishes a linear and non-linear equation $\left(2^{\text {nd }}\right.$ order polynomial) between $\%$ of PSF and $\%$ of households and per capita monthly expenditure based on principles of regression analysis (Chapra and Canale 2010). Using these equations one can easily determine the optimal value of PSF which is indirectly connected to poverty level. The validity of the fitted equation is studied with respect to correlation coefficient $(r)$ and standard error of estimate $\left(\mathrm{s}_{\mathrm{y} / \mathrm{x}}\right)$. These results will be very useful to a wide cross section of the community.
\end{abstract}

KEYWORDS: Fishermen, Household expenditure, Mathematical Analysis, Poverty, PSF (Proportion Spent on Food), Specific communities

\section{Introduction}

This research comes under the general heading of Political Economy. The main objective of this study is to critically examine the socio-economic structure and living conditions of fisherman in Andhra Pradesh, India. The areas of study are chosen based on the concentration of fishermen. The other objectives of this study are to measure the income, deprivation of poverty among the sectors in Andhra Pradesh with high population of fisherman. In other words, the poverty issue is studied implicitly. This study is somewhat similar to the study done by the second author of this paper dealing with poverty indices in various states of United States of America (Putcha 2008). In that study, an equation has been developed relating poverty index to the two critical parameters, namely, family size and family income and hence that study was more theoretical in nature. However, in this study, lot of practical data of a particular section of the population, fisherman, has been collected regarding their economic level. Another important parameter that has been used in this study, is what is known, PSF (Percentage Spent on Food), which directly connects to poverty. This is because for any person, most of the monthly income is spent on food. Hence the study concentrates on the parameters connected with PSF.

\section{Methodology}

The basic steps followed in doing this research are given below.

1. Identify the critical parameters that affect Percentage Spent on Food (PSF).

2. These are - Mean per capita total expenditure and \% of households (people in a house hold).

3. Once this data is collected, next step is to establish a mathematical equation between PSF, dependent variable $(\mathrm{y})$ and $\%$ of household, an independent variable (x). Actual plots for the collected data are also reported in this study. Both linear and nonlinear equations are fitted.

4. Develop a mathematical equation between PSF (dependent variable y) and Mean per capita total expenditure (independent variable $\mathrm{x}$ ). Once again, actual plots for the collected data are also reported in this study. In this phase also, both linear and nonlinear equations are fitted. 
5. Since the validity check for a good fit is judged mainly by correlation coefficient ( $\mathrm{r}$ ), being $>=0.9$, this test is performed. The other criteria of standard error of estimate (sy/x) are not used in this study.

\section{Results}

Table 1 shows the data for $\%$ of household (x) and $\%$ of PSF (y).

Table 1: \% of household (x) and \% PSF (Y) (actual)

\begin{tabular}{|c|c|}
\hline \% of household (x) & \% of PSF (y) \\
\hline 3 & 84.4 \\
\hline 2 & 77.8 \\
\hline 1 & 79.1 \\
\hline 3 & 83.8 \\
\hline 4 & 80.8 \\
\hline 11 & 83.4 \\
\hline 15 & 82.4 \\
\hline 17 & 81.3 \\
\hline 17 & 77.3 \\
\hline 10 & 70 \\
\hline 8 & 61.9 \\
\hline 4 & 55 \\
\hline 3 & 42.2 \\
\hline 2 & 36.2 \\
\hline
\end{tabular}

Figura 1 shows the plot of actual data and the fitted equation based on regression analysis.

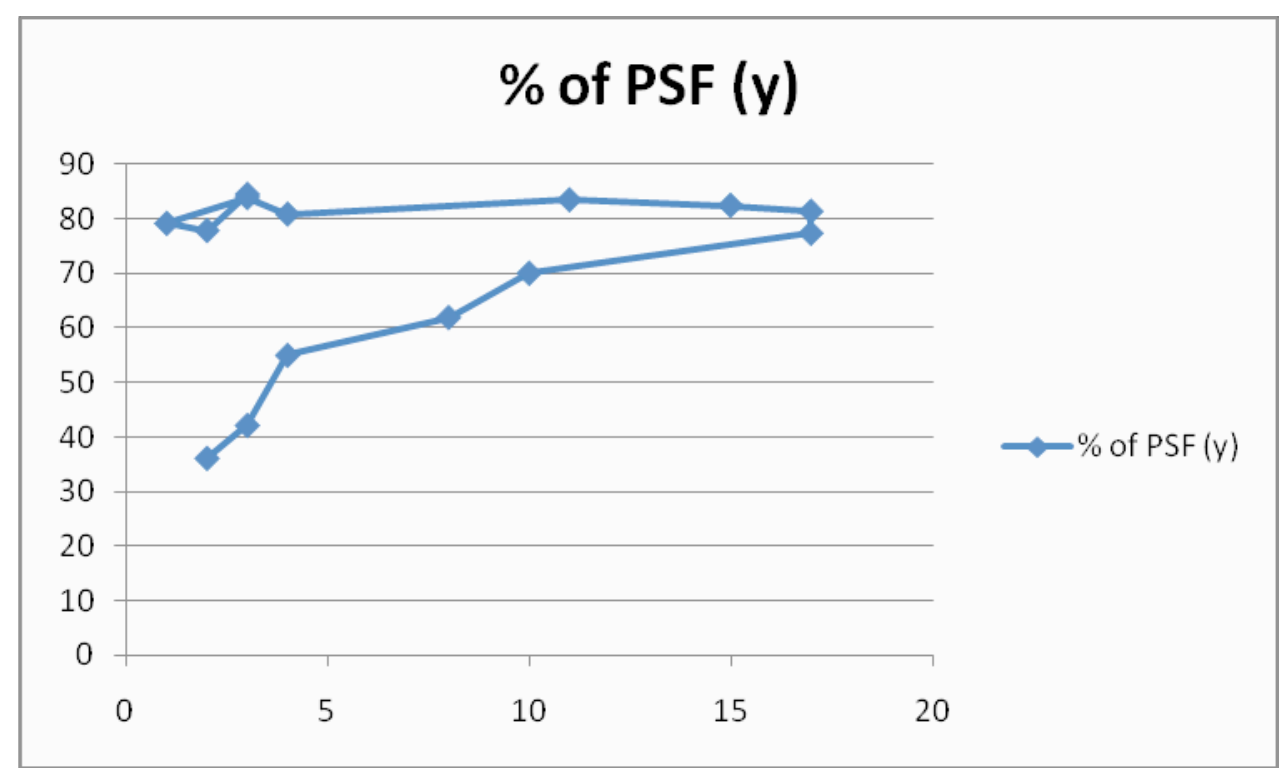

Figura 1. Variation of \% PSF and \% of household 
The linear equation is obtained using the principles of regression analysis well documented in literature. It is given as,

$\%$ PSF $=64.40+0.9392(\%$ of households $)$

The correlation coefficient $r$ is 0.92

Since $r>=0.9$, the fitted equation is acceptable.

The corresponding nonlinear equation is:

$y=66.58+0.0984(\%$ of households $)+0.0463(\% \text { of households })^{2}$

Table 2 shows the data for capital expenditure (x) and \% PSF (y).

Table 2. Capita Expenditure (x) and \% PSF (Y) (actual)

\begin{tabular}{|c|c|}
\hline & \\
Capita Expenditure (x) & \% of PSF (y) \\
\hline 52.4 & 84.4 \\
\hline 70.35 & 77.8 \\
\hline 82.5 & 79.1 \\
\hline 102.7 & 83.8 \\
\hline 113.35 & 80.8 \\
\hline 120.8 & 83.4 \\
\hline 155.5 & 82.4 \\
\hline 191.85 & 81.3 \\
\hline 245.05 & 77.3 \\
\hline 318.35 & 70 \\
\hline 424.15 & 61.9 \\
\hline 595.55 & 55 \\
\hline 853.55 & 42.2 \\
\hline 1832 & 36.2 \\
\hline
\end{tabular}

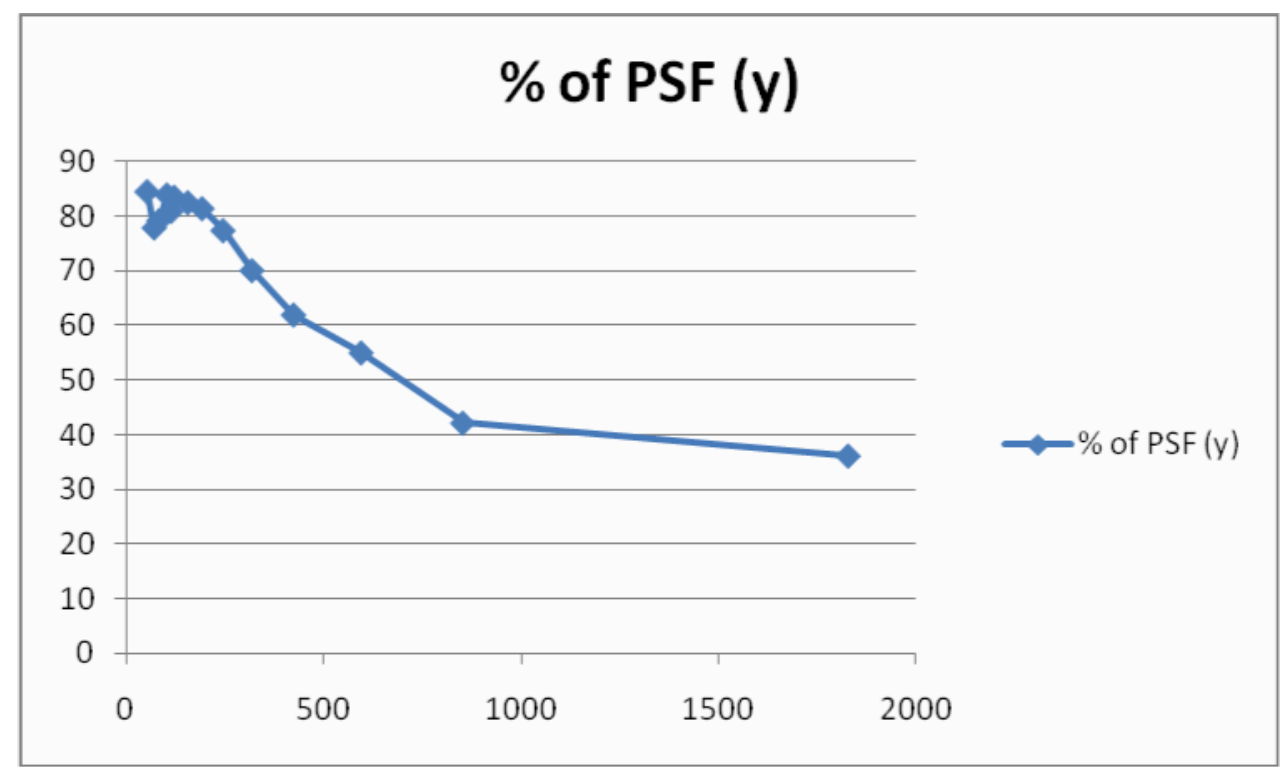

Figura 2. Variation of \% PSF and Capita expenditure 
The linear equation is obtained using the principles of regression analysis well documented in literature. It is given as,

$\%$ PSF $=82.383-0.0305$ (capital expenditure)

The correlation coefficient ( $\mathrm{r}$ ) is obtained as 0.9128 .

Since $r>=0.9$, the fitted equation is acceptable.

The nonlinear equation is: $\mathrm{y}=89.32-0.071$ (capital expenditure) +0.00002277 (capital expenditure) ${ }^{2}$

\section{Discussion of Results and Conclusions}

Mathematical tools have been used to study in depth the relation between Percentage Spent on Food (PSF) and $\%$ of households and per capita total expenditure. The results using the principles of regression analysis showed that mean per capita total expenditure is more critical than \% of households. The methodology used is general in nature and can be applied to any problem even though it has been used to study the poverty level of fisherman. The results obtained are very useful to a wide and diverse cross section of the society.

\section{References}

Chapra, S.C and Canale, R.P. 2010. Numerical Methods for Engineers. New York: McGraw Hill. Rao, M.R 1998. Poverty Levels And Marketing Problems of Fisherman in Andhra Pradesh.

Putcha, C.S. 2008. "Mathematical Formulation of Poverty Index." European Journal of Scientific Research (EJSR), Vol. 20(2). 